\title{
Early detection and management of symptoms using an interactive smartphone application (Interaktor) during radiotherapy for prostate cancer
}

\author{
Kay Sundberg ${ }^{1,2}$ - Yvonne Wengström ${ }^{1,2}$ - Karin Blomberg ${ }^{3}$. \\ Maria Hälleberg-Nyman ${ }^{3}$. Catharina Frank ${ }^{1}$ • Ann Langius-Eklöf ${ }^{1}$
}

Received: 19 August 2016 / Accepted: 6 February 2017 / Published online: 24 February 2017

(C) The Author(s) 2017. This article is published with open access at Springerlink.com

\begin{abstract}
Purpose Patients undergoing radiotherapy for prostate cancer suffer from a variety of symptoms which influence healthrelated quality of life. We have developed an application (Interaktor) for smartphones and tablets for early detection, reporting and management of symptoms, and concerns during treatment for prostate cancer. The study evaluates the effect on symptom burden and quality of life when using the application for real-time symptom assessment and management during radiotherapy for localized prostate cancer.

Methods A non-randomized controlled study was used at two university hospitals in Sweden where 64 patients constituted a control group and 66 patients made up an intervention group. The intervention group was asked to report symptoms via the application daily during the treatment as well as 3 weeks after. The EORTC QLQ-C30 and its module PR25 and the Sense of Coherence questionnaire were administered at three time points in both groups.

Results The intervention group rated significantly lower levels of fatigue and nausea at the end of radiotherapy. Moreover, they had significantly less burden in emotional functioning, insomnia, and urinary-related symptoms at the end of treatment as well as 3 months later compared with the control group. In the multivariate analyses, with education and
\end{abstract}

Kay Sundberg

kay.sundberg@ki.se

1 Department of NVS, Division of Nursing, Karolinska Institutet, 23 300, Huddinge, 14183 Stockholm, Sweden

2 Radiumhemmet, Karolinska University Hospital, Stockholm, Sweden

3 Faculty of Medicine and Health, School of Health Sciences, Örebro University, Örebro, Sweden sense of coherence as covariates, the intervention group still significantly rated emotional functioning ( $p=0.007)$, insomnia $(p=0.017)$, and urinary-related symptoms $(p=0.008)$ as better than the control group at T2.

Conclusion Study findings suggest that Interaktor could be an efficient mHealth tool for facilitating supportive care needs during cancer treatment.

Keywords Prostate cancer · Radiotherapy · Symptom reporting $\cdot$ Symptom management $\cdot$ Interactive smartphone application

\section{Introduction}

Through early diagnosis and improved therapies for patients with localized prostate cancer, many men will be cured [1]. The patients typically receive radiotherapy, often in combination with hormonal treatment, which causes side effects that significantly may impact the patients' health-related quality of life (HRQoL) [2, 3]. During the treatment period, the patients are mostly cared for as outpatients. This puts demands on both the patient to be an expert on his own health and on the health care setting to deliver safe care. One concern is the patients' unmet needs regarding information and knowledge of symptoms and side effects of the illness and its treatment [4]. Another concern is the lack of strategies for symptom management as well as self-care to alleviate symptom distress following treatment $[5,6]$. Therefore, regular symptom assessment and purposeful information regarding self-management activities are important factors in the management of prostate cancer and treatment-related consequences $[4,6]$.

A developing focus in cancer care is to systematically integrate the collection of patient-reported outcomes (PRO) in clinical practice as the foundation for care planning and 
evaluation of treatment efficacy [7]. PROs can be any aspect of a patient's health status (including symptoms, functioning, and HRQoL) that is reported by the patient without any interpretation of the responses by a caregiver or anyone else [8]. Studies show that clinical routine use of PROs may facilitate the detection of problems, provide information on impact of treatment, monitor quality improvement, enhance patientclinician communication, promote shared decision making, and improve patient satisfaction $[9,10]$.

Information and communication technology (ICT) is becoming an integral part of modern health care [11]. The ICTbased solutions utilize digital technology access to Internetbased programs (eHealth) and use of mobile devices, platforms, and applications (mHealth). These have various purposes, including assisting with self-management, delivering real-time data on a patient's health condition to both the patient and caregivers, and storing personal health information in an easily accessible format [11]. Collecting PROs through different ICT applications has previously been tested in cancer care with, for example, touch screens [12] and Web-based systems [13]. Hilarius et al. (2008) support the use of cancer-specific assessments as a means of facilitating discussions of HRQoL issues, by increasing nurses' awareness of their patients' problems. In a recent RCT, including patients with breast and prostate cancer, a Web-based interactive health communication application was tested [13]. Symptoms during treatment were monitored, and self-management support, communication with expert cancer nurses, and an e-forum with other patients were provided. The results showed HRQoL scores in slight favor of the intervention group overall, although differences were statistically significant only for the global symptom distress subscale. In a study with heart failure patients, self-care was improved through the use of a mobile phone-based system with instructions to the patients about how to appropriately modify lifestyle behaviors [14]. Another study used a mobile phone-based questionnaire for reporting symptoms when receiving chemotherapy for colorectal, lung, or breast cancer [15]. The findings showed improved symptom management and communication between patients and health care professionals, and the patients also reported that they felt reassured that their symptoms were monitored while at home. These studies show promising results, but it has also been suggested that applications for smartphones are effective tools to involve the patients and enhance their notions of participation and respect [16]. However, interactive smartphone applications facilitating support needs by exchanging health information in real-time between patients and nurses have rarely been studied.

Therefore, in co-design with patients and health care personnel, we have developed [5] and tested [17] an interactive application (Interaktor) for smartphones and tablets. Daily reports via the application enable instant support from a nurse in early detection and management of symptoms and concerns in real-time during treatment for prostate cancer. The project is conducted in cooperation with Health Navigator, a Swedish company specializing in health care management and new innovative care solutions. Interaktor includes symptom assessment, a risk assessment model for alerts directly to a nurse, continuous access to evidence-based self-care advice, and links to relevant Web sites directly related to reported symptoms and concerns.

Our feasibility study showed high user-friendliness and acceptability by both patients and nurses when used during radiotherapy for prostate cancer [17]. The objective of this study was to evaluate the effect on symptom burden as well as health-related quality of life when using the application for real-time symptom assessment and management during adjuvant radiotherapy for localized prostate cancer.

\section{Methods}

\section{Study design and participants}

A non-randomized controlled design was used including patients from two sites, one urban and one rural. Data was collected at three time-points in both an intervention group and a control group between April 2012 and October 2013: at T1 baseline, at T2 after end of treatment, and at T3 3 months after end of treatment.

A total of 130 patients with prostate cancer from two university hospitals in Sweden participated in the study: intervention group (IG), $n=66$ (77\%); control group (CG), $n=64$ $(80 \%)$. The sample size was considered sufficient as compared with a similar study of patients with heart failure, showing that 34 patients/group is enough to reach effect size of 1 in the main outcome of self-reported health [14].

The study was historically controlled, whereas the data for the CG was collected first, and when completed, the inclusion in the IG began (Fig. 1). Inclusion criteria were (1) a localized prostate cancer (T1c-T3, N0M0); (2) eligibility for curative radiotherapy (RT); (3) being able to read and understand Swedish; and (4) being considered physically, psychologically, and cognitively able to participate in the study. The patients were treated according to the National guidelines for prostate cancer [18] with external beam radiation therapy (EBRT) 78 Gray/39 fractions with or without a combination of iridium high-dose-rate brachytherapy (HDR) and neoadjuvant hormone therapy (HT). The patients treated solely with EBRT were treated for a period of 8 weeks, whereas those who received a combination of HDR and the EBRT lasted for 5 weeks. The treatment protocol was the same for both sites. During RT, the standard care for all patients comprises regular contact with therapy staff and access to a contact nurse regarding any treatment-related concerns. No regular medical appointments or other standard procedures are included in the care during the treatment period. The mean age (range) of all patients included was 69 years (52-82) (Table 1). 
Fig. 1 Flow chart of patient participation

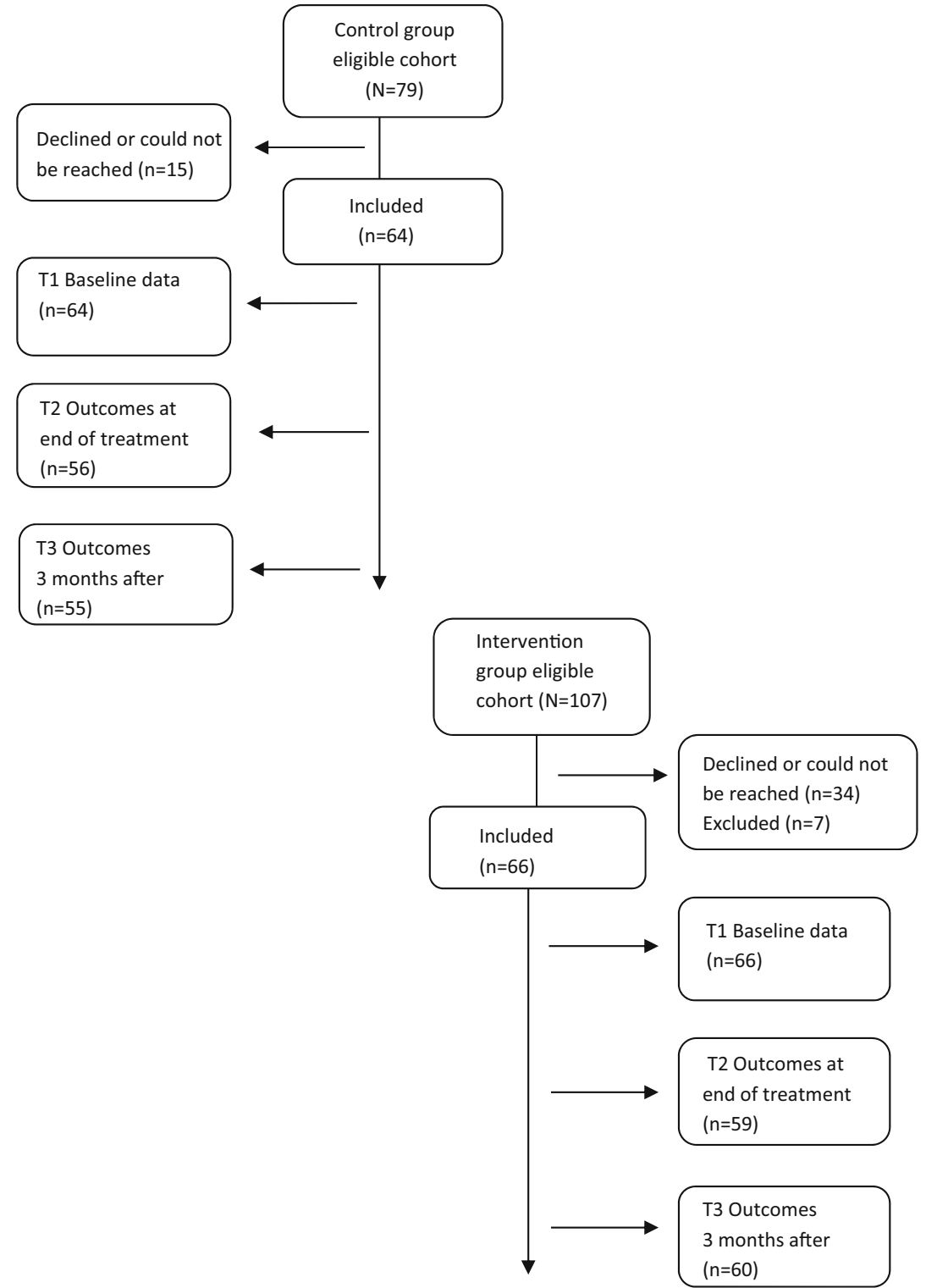

April 2012

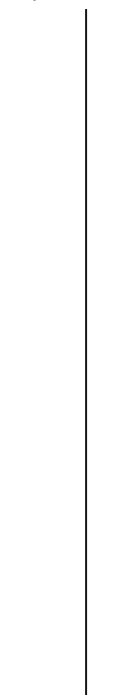

December 2012

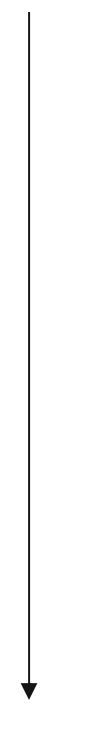

October 2013
The patients who were listed for RT at the two sites were consecutively included in the study. The coordinators at the RT units identified the patients and provided oral and written information about the study. The researchers subsequently called the patients, and if they were considered to fulfill the inclusion criteria, they were asked to participate in the study. Written informed consent was obtained from all study participants. Ethical approval was obtained from the Regional Ethical Review Board of Uppsala University (dnr 2011/256).

\section{The intervention—real-time symptom assessment}

The patients in the IG were equipped with a smartphone and were given thorough instructions how to use the installed app and an opportunity to send a test report under supervision. The patients were provided with a checklist including a phone number in case they needed to get in contact for any technical support. They were asked to send daily reports at any time point when they felt unwell for the entire period of RT (5-8 weeks), as well as for the following 3 weeks after treatment. The patients were informed that during the study period, the alerts (via text messages) were monitored only during office hours, and so were instructed to contact the clinic for emergencies outside those hours. A reminder message was sent if a report had not been submitted. At the clinic, the nurses who were the patients' contact nurses viewed the reported symptoms via the Web interface and, in case of an alert, contacted the patient by telephone to discuss the reported 
Table 1 Clinical and sociodemographic characteristics of patients in the intervention group $(n=66)$ and the control group $(n=64)$

\begin{tabular}{|c|c|c|c|c|c|}
\hline$\overline{ }$ & \multicolumn{2}{|c|}{ Intervention group } & \multicolumn{2}{|c|}{ Control group } & \multirow{3}{*}{$\begin{array}{l}p \\
0.805^{*}\end{array}$} \\
\hline mean $(\mathrm{SD})$ & 69 & $(5.8)$ & 69 & $(6.2)$ & \\
\hline median (range) & 70 & $(53-82)$ & 71 & $(52-80)$ & \\
\hline \multicolumn{6}{|l|}{ Health Literacy-Index } \\
\hline mean (SD) & 318 & $(609)$ & 476 & $(855)$ & $0.232^{*}$ \\
\hline Living situation, $n(\%)$ & & & & & $0.238^{* *}$ \\
\hline married/living with partner & 49 & $(75)$ & 47 & 73 & \\
\hline Alone & 9 & (14) & 13 & 20 & \\
\hline Other & 8 & (11) & 4 & 6 & \\
\hline Education level, $n(\%)$ & & & & & $0.017^{* *}$ \\
\hline Junior compulsory & 9 & (14) & 22 & 36 & \\
\hline Senior high school & 23 & (36) & 17 & 28 & \\
\hline Postgraduate/university & 32 & $(50)$ & 22 & 36 & \\
\hline Occupation, $n(\%)$ & & & & & $0.428^{* * *}$ \\
\hline Working & 13 & $(20)$ & 9 & $(15)$ & \\
\hline Retired & 47 & $(71)$ & 50 & $(78)$ & \\
\hline Sick leave & 1 & (1) & 1 & (1) & \\
\hline Other & 5 & (8) & 4 & (6) & \\
\hline Clinical T stage, $n(\%)$ & & & & & $0.622^{* *}$ \\
\hline 1 & 16 & (24) & 18 & $(28)$ & \\
\hline 2 & 29 & (44) & 25 & $(39)$ & \\
\hline 3 & 17 & (26) & 20 & $(31)$ & \\
\hline Missing & 4 & (6) & 1 & (2) & \\
\hline Gleason, $n(\%)$ & & & & & $0.300^{* *}$ \\
\hline 6 & 10 & $(15)$ & 5 & $(8)$ & \\
\hline 7 & 28 & $(42)$ & 36 & $(56)$ & \\
\hline 8 & 13 & $(20)$ & 13 & $(20)$ & \\
\hline 9 & 14 & $(21)$ & 7 & (11) & \\
\hline 10 & 1 & (2) & 1 & (2) & \\
\hline Missing & & & 2 & (3) & \\
\hline Treatment, $n(\%)$ & & & & & $0.130^{* * *}$ \\
\hline Neoadjuvant hormonal therapy (HT) & 50 & (76) & 40 & $(62)$ & \\
\hline External beam radiotherapy (EBRT) & 20 & $(30)$ & 22 & $(34)$ & \\
\hline Brachytherapy combined with EBRT & 46 & $(70$ & 44 & $(66)$ & \\
\hline
\end{tabular}

\footnotetext{
* Tested for differences by Student's $t$ test
}

*** Tested for differences by $\chi^{2}$ statistics problems. The patients were also instructed about the selfcare advice and that they could view their own symptomhistory in graphs over time.

The symptom assessment in the application included 15 identified and tested questions regarding the following: bladder $(n=4)$ and bowel $(n=4)$ function, fatigue, pain, anxiety, distress, sleep, and flushing [5, 17]. The last question "other symptoms or concerns to report" was an open question providing the opportunity to write a message. The structure of the assessments was based on a standardized symptom and HRQoL questionnaire model [19]; in other words, the questions addressed occurrence, frequency, and distress level. For example, "Do you experience urinary urgency?" If the answer was yes, the patient was asked how often it occurs, rated by frequency: never, sometimes, rather often, or very often; additionally, they rated how distressing the symptom was: not at all, a little, rather, or very much. The risk assessment model, based on symptom occurrence and frequency, sent two kinds of alerts: yellow and red. For example, a yellow alert appeared if the patient reported urinary retention "rather often," and a red alert, when the patient reported urinary retention "very often." A yellow alert indicated that the nurse should contact the patient sometime during 
the same day. A red alert had a higher priority, meaning contact should be made within an hour.

\section{Measurements}

Medical and demographic data were collected at baseline in both groups from the medical records. A questionnaire measuring Health Literacy, defined to cover cognitive and social skills that determine the motivation and ability to acquire understand and use information in a way that promotes and maintains good health [20], was included at baseline. A Health Literacy-Index was categorized from a tested scale [21] on three levels where sums $<100$ equals sufficient health literacy, $>110$ but $<1000$ equals problematic health literacy, and $>1000$ equals inadequate health literacy [22].

\section{EORTC QLQ-C30 and EORTC QLQ-PR25}

The EORTC QLQ-C30 was developed for measurement of HRQoL in cancer patients and has been extensively validated [23]. The 30-item questionnaire incorporates five functional scales (physical, role, emotional, social, and cognitive), eight symptom scales (fatigue, nausea and vomiting, pain, insomnia, appetite loss, constipation, diarrhea), financial impact of the disease, and a global health status/QoL scale. Additionally, the EORTC QLQ-PR25 (25 items) was used for assessing specific prostate cancer symptoms related to treatment such as sexual function and activity and bladder and bowel problems [24]. The items have response categories with four levels from "not at all" to "very much," except for two items, which use seven levels from "very poor" to "excellent." Higher scores reflect better functioning in the functional scales as well as the global health status scale and more symptoms (urinary, bowel, hormonal treatment-related symptoms) as well as higher levels of sexual functioning.

SOC

The SOC scale developed by Antonovsky [25] assesses a person's overall orientation to life, as an inner resource for coping with stressful life events. The SOC concept is built on how comprehensible, manageable, and meaningful life appears. The scale consists of 13 items that comprise three components: comprehensibility (to which 5 items contribute), manageability (4 items), and meaningfulness (4 items). The respondents indicate agreement or disagreement on a 7 category scale, with two anchoring responses tailored to the content of each item. Five items are reversed before summing the total score. The total score can range from 13 to 91 , and a higher score indicates a higher SOC. The scale has been translated into more than 33 languages and been tested for reliability and validity, as well as for cross-cultural adaptation in several settings, while using cohorts both from within health care facilities and from the general populations in different countries [26]. Studies show that a high SOC is correlated to better health and HRQoL within different samples [27] as well as in men with prostate cancer [28].

\section{Statistical analysis}

Chi-square statistics were performed to compare proportions of categorical variables. The items of the EORTC QLQ-C30 and the EORTC QLQ-PR25 were scaled according to the scoring manual, and raw scores were linearly transformed into 0-100 scales [29]. Both within-group and between-group analyses were performed. The variables in the functional and symptom scales, which in a Student's $t$ test showed significant mean differences between the groups (Table 3), were run in general linear model (GLM) repeated measures as dependent variables with group as a factor. Because "education" showed significant group difference $(p=0.017)$ at baseline (Table 1), we included this as a covariate in the analyses. Subsequently, with regard to the predictive validity, the SOC has shown in longitudinal studies for a good HRQoL [27, 30], additional GLM repeated measure analyses were performed while also adding SOC as a covariate. Statistical calculations were performed using the Statistical Package for Social Sciences, Windows version 22.0. A statistical significance level of $p<0.05$ was applied in all analyses.

\section{Results}

The IG and the CG were well balanced regarding demographics and clinical characteristics, except that the $\mathrm{CG}$ showed a statistically significant lower level of education (Table 1). At baseline (T1), there were no statistically significant differences between the IG and the CG regarding any of the outcome measures (Table 2).

\section{Differences within groups}

There were no significant differences regarding the functional scales within the IG over time: from T1 to T3. Meanwhile, the patients in the CG rated significantly decreased global quality of life $(p=0.015)$ and role $(p=0.004)$, as well as emotional $(p=0.026)$ and social $(p=0.004)$ functioning. Regarding the symptom scales over time, the CG reported increased fatigue $(p=0.001)$ and insomnia $(p=0.05)$. Both groups reported a significant increase of diarrhea, urinary symptoms, bowel symptoms, hormone-related symptoms, and sexual activity (Table 2).

\section{Differences between groups}

The CG rated significantly worse emotional functioning at the end of the radiotherapy ( $p=0.002)$, as well as 3 months later $(p=0.26)$ compared with the IG. The CG also had a higher level of fatigue $(p=0.047)$ and nausea $(p=0.038)$ at the end 
Table 2 Between- and within-group differences in mean scores of EORTC QLQ-C30 + EORTC QLQ-PR 25 and SOC in intervention group (IG) and control group (CG)

\begin{tabular}{|c|c|c|c|c|c|c|c|c|c|c|c|}
\hline & \multicolumn{3}{|l|}{$\mathrm{T} 1$} & \multicolumn{3}{|l|}{$\mathrm{T} 2$} & \multicolumn{3}{|l|}{$\mathrm{T} 3$} & \multirow[b]{2}{*}{$\mathrm{P}_{-}^{a}$} & \multirow[b]{2}{*}{$\mathrm{P}_{-}^{\mathrm{b}}$} \\
\hline & IG $(n=64)$ & $\mathrm{CG}(n=62)$ & $p$ & $\mathrm{IG}(n=51)$ & $\mathrm{CG}(n=59)$ & $p$ & $\mathrm{IG}(n=61)$ & $\mathrm{CG}(n=55)$ & $p$ & & \\
\hline \multicolumn{12}{|l|}{ EORTC QLQ-C30 } \\
\hline \multicolumn{12}{|l|}{ mean $(S D)$} \\
\hline Global QoL & $74.9(20.2)$ & $71.9(17.1)$ & .377 & $69.8(20.5)$ & $66.0(19.1)$ & .315 & $74.2(18.8)$ & $69.2(19.2)$ & .165 & & .015 \\
\hline Finance & $8.9(23.2)$ & $9.0(44.1)$ & .982 & $14.4(32.1)$ & $5.1(17.3)$ & .057 & $6.0(18.8)$ & $6.0(18.1)$ & .986 & .004 & \\
\hline \multicolumn{12}{|l|}{ Functional scales } \\
\hline Physical & $90.7(13.3)$ & $87.6(15.3)$ & .228 & $87.1(16.8)$ & $85.5(15.8)$ & .598 & $87.6(17.9)$ & $83.9(17.2)$ & .277 & & \\
\hline Role & $86.5(21.4)$ & $86.5(20.7)$ & .999 & $79.2(27.4)$ & $75.8(25.6)$ & .911 & $84.2(23.7)$ & $82.4(24.1)$ & .312 & & .004 \\
\hline Emotional & $85.6(17.6)$ & $80.8(19.6)$ & .155 & $90.2(18.4)$ & $77.7(22.2)$ & .002 & $90.0(18.0)$ & $82.6(17.6)$ & .026 & & .026 \\
\hline Cognitive & $87.8(18.1)$ & $88.3(14.5)$ & .838 & $86.9(16.7)$ & $86.0(16.3)$ & .763 & $86.6(2.1)$ & $85.7(13.6)$ & .746 & & \\
\hline Social & $79.7(23.1)$ & $85.8(16.3)$ & .092 & $77.5(21.8)$ & $75.3(22.7)$ & .619 & $78.3(23.0)$ & $80.1(21.9)$ & .680 & & .004 \\
\hline \multicolumn{12}{|l|}{ Symptom scales } \\
\hline Fatigue & $20.1(18.8)$ & $23.8(19.0)$ & .274 & $25.7(21.5)$ & $34.3(22.9)$ & .047 & $22.8(19.5)$ & $29.4(19.9)$ & .073 & & .001 \\
\hline Nausea & $1.6(5.7)$ & $1.6(5.0)$ & .979 & $1.7(5.9)$ & $5.3(11.7)$ & .038 & $3.0(13.8)$ & $3.3(9.2)$ & .882 & & \\
\hline Pain & $17.5(23.5)$ & $15.1(20.7)$ & .547 & $19.0(24.9)$ & $21.9(22.1)$ & .512 & $13.7(20.5)$ & $17.9(24.1)$ & .312 & & \\
\hline Dyspnea & $21.4(24.8)$ & $19.0(23.7)$ & .593 & $23.3(27.7)$ & $20.0(21.4)$ & .462 & $24.6(25.7)$ & $18.8(22.0)$ & .197 & & \\
\hline Insomnia & $22.9(26.5)$ & $25.4(26.6)$ & .599 & $18.6(25.7)$ & $33.9(32.2)$ & .005 & $18.6(24.7)$ & $29.6(30.8)$ & .035 & & .051 \\
\hline Appetite & $5.2(17.0)$ & $4.2(16.4)$ & .743 & $5.6(20.5)$ & 7. $2(17.5)$ & .633 & $4.4(15.5)$ & $4.3(11.3)$ & .984 & & \\
\hline Constipation & $6.8(18.0)$ & $10.0(19.5)$ & .326 & $10.0(20.6)$ & $16.1(26.4)$ & .160 & $6.6(17.0)$ & 9.1 (19.7) & .459 & & \\
\hline Diarrhea & $6.3(14.4)$ & $7.4(17.4)$ & .683 & $20.3(25.9)$ & $24.9(30.7)$ & .402 & $12.0(20.2)$ & $13.7(20.9)$ & .661 & .027 & .017 \\
\hline \multirow{2}{*}{\multicolumn{12}{|c|}{$\begin{array}{l}\text { EORTC QLQ-PR } 25 \\
\text { mean }(S D)\end{array}$}} \\
\hline & & & & & & & & & & & \\
\hline Sexual activity & $76.3(22.9)$ & $77.3(23.7)$ & .817 & $85.0(17.4)$ & $85.1(18.0)$ & .958 & $82.8(18.2)$ & $86.3(18.2)$ & .310 & .025 & .004 \\
\hline Sexual function & $61.7(14.8)$ & $55.7(14.5)$ & .412 & $60.9(17.5)$ & $55.6(18.5)$ & .442 & $51.7(15.7)$ & $53.7(21.3)$ & .750 & & \\
\hline Urinary symptoms & $16.4(14.1)$ & $20.0(15.9)$ & .176 & $32.1(19.4)$ & $43.6(23.1)$ & .005 & $20.6(15.5)$ & $27.6(19.9)$ & .038 & .025 & .002 \\
\hline Bowel symptoms & $5.1(8.5)$ & $4.1(7.9)$ & .494 & $11.6(12.3)$ & $15.7(17.0)$ & .141 & $8.1(12.9)$ & $7.9(9.2)$ & .934 & .028 & .018 \\
\hline Hormone related & $19.7(13.5)$ & $18.1(16.1)$ & .574 & $21.4(10.9)$ & $22.2(15.5)$ & .736 & $25.7(14.1)$ & $26.5(15.5)$ & .772 & .001 & .002 \\
\hline Incontinence aid & 0.0 & $15.1(23.0)$ & .541 & $16.7(18.2)$ & $22.2(20.6)$ & .572 & $16.7(19.2)$ & $7.4(14.7)$ & .358 & & \\
\hline \multicolumn{12}{|l|}{ SOC } \\
\hline mean $(S D)$ & $74.9(11.3)$ & $71.5(11.2)$ & .116 & $74.2(9.8)$ & $72.0(12.3)$ & .283 & $74.1(11.2)$ & $72.3(11.9)$ & .433 & & \\
\hline
\end{tabular}

$P_{-}{ }^{a}$ IG over time, $P_{-}^{b}$ CG over time

of treatment. Insomnia and urinary symptoms were more frequently reported by the $\mathrm{CG}$ both at the end of treatment ( $p=0.005$ and $p=0.005$, respectively) and 3 months later ( $p=0.035$ and $p=0.038$, respectively) (Table 2 ).

In the multivariate analyses, with education as a covariate, the IG still significantly rated emotional functioning ( $p=0.007)$, insomnia ( $p=0.004)$, and urinary-related symptoms ( $p=0.003$ ) as better than the CG at T2. When adding the SOC scale as a covariate, SOC was a significant predictor in the dependent scales, except for nausea at T2, and the statistically significant differences for emotional functioning ( $p=0.007)$, insomnia $(p=0.017)$, and urinary-related symptoms $(p=0.008)$ at T2 remained. Thus, the IG rated better emotional functioning and fewer problems with sleep and urinary symptoms than the CG did at the end of treatment (Table 3). An illustration of the findings is presented in Fig. 2.

\section{Discussion}

This study provides novel results for the effects on symptom burden and HRQoL when using a smartphone app for real-time symptom assessment and management during treatment in patients with localized prostate cancer. The main finding was that the intervention group reported less symptom burden at the end of treatment in emotional functioning, insomnia, and urinary-related symptoms compared to the control group. Furthermore, within- 
Table 3 General linear model test between subjects

\begin{tabular}{lllll}
\hline & $\begin{array}{l}\text { Group } \\
p\end{array}$ & $\begin{array}{l}\text { Education } \\
p\end{array}$ & $\begin{array}{l}\text { SOC } \\
p\end{array}$ & $\begin{array}{l}\text { Model } \\
\text { Adj } R^{2}\end{array}$ \\
\hline Emotional T1 & .810 & .447 & .000 & .229 \\
Emotional T2 & .007 & .712 & .000 & .355 \\
Emotional T3 & .506 & .332 & .000 & .248 \\
Fatigue T1 & .999 & .982 & .000 & .102 \\
Fatigue T2 & .128 & .727 & .000 & .237 \\
Fatigue T3 & .218 & .765 & .000 & .153 \\
Nausea T1 & .718 & .935 & .024 & .022 \\
Nausea T2 & .331 & .505 & .131 & .015 \\
Nausea T3 & .942 & .718 & .000 & .122 \\
Insomnia T1 & .376 & .285 & .000 & .110 \\
Insomnia T2 & .017 & .795 & .001 & .140 \\
Insomnia T3 & .213 & .551 & .002 & .092 \\
Urinary symptoms T1 & .900 & .069 & .000 & .137 \\
Urinary symptoms T2 & .008 & .832 & .001 & .169 \\
Urinary symptoms T3 & .303 & .174 & .000 & .167 \\
\hline
\end{tabular}

Analyzed by multivariate tests with group as factor and education and SOC as covariates

group findings showed that the control group was more negatively affected by treatment over time as compared with the intervention group.

Our results confirm optimistic outcomes at the end of treatment when using the application, although results are not persistent at the 3-month follow-up. However, there was also a trend of better scores in many of the symptom and functional scales at 3 months post-treatment. This is an encouraging finding, as patients who experience a high symptom burden are more at risk of developing symptomrelated distress [6]. Also, urinary problems such as incontinence and urinary urgency have been shown to be very common long-lasting symptoms after treatment with a negative influence on HRQoL $[2,31]$.

Sleeping problems studied in patients with nonmetastatic cancer have been shown to be strongly associated with anxiety and depression [32]. In a recent review of supportive care during and after treatment of prostate cancer, men described an increased need for emotional support when experiencing treatment side effects [33]. Early identification and management of symptoms might be especially important, as under-diagnosed symptoms often have a negative impact on the individual's HRQoL and recovery, and last for a long time after treatment [34]. Reporting symptoms daily enabled instant support from a nurse when needed. When the nurses received an alert, the patient was contacted and they discussed how the problem could be alleviated. If the patient needed a medication, the nurse consulted a doctor. In other cases, nursing actions, by either seeing the patient or talking on the phone, were instigated. The selfcare advice directly related to the reported concerns was another important asset that could enable the patients to take an active part. Guiding patients with cancer in selfcare management is essential for functional status and HRQoL [35]. In our previous study, we found that strategies for self-care management for patients with prostate cancer are rare in the literature, and in interviews with patients, they expressed scarce experience of support or information about self-care activities during treatment [5]. Furthermore, the patients reported that it was sometimes difficult to get in touch with health care professionals and that they were lacking sufficient information about their symptoms. In their review, Mazzarello et al. [33] also showed that the men reported poor communication with health professionals about the potential severity and duration of their symptoms. This highlights the urgent need for improved access to cancer specialist nurses, as well as individually tailored supportive care for treatment of side effects. In person-centered care emphasis is on the interaction between the patient and the health care givers enabling the patient to be a partner rather than a passive receiver of care [36]. A mHealth tool like Interaktor could be a facilitator for personcentered care, and it can be used in a wide range of settings tailored to suit any group of patients.

A methodological consideration is the potential confounders not controlled for following the design. A randomly assigned sample is of course optimal, although the spillover effect must always be taken into account. Still, the treatment regime and the standard clinical procedures, having access to doctors and nurses, were the same for both groups of patients. The two groups were comparable in many variables except that educational level in the control group was significantly lower than in the intervention group, which may influence their ratings of selfreported HRQoL. Strength is, however, when controlling for educational level as well as the patients' degree of SOC, both strongly related to HRQoL [27, 37], the group effect remained in one functional and two symptom scales. In recent literature, there is a general view that educational level is not really a holdback for using mHealth but rather a significant factor for satisfaction of such use [38]. Literature also reveals health literacy to be a factor for processing the meaning and usefulness of health information and services [20, 39]. In our study, the degree of health literacy was not significantly different between the groups at baseline indicating that they were equally prone to understand and adhere to standard care of symptom management [20]. Still, due to lack of familiarity of technology mobile-based symptom, reporting may not be feasible for all patients which should be taken into account for future implementation. 
Fig. 2 Between-group ratings of quality of life and symptoms from the EORTC questionnaire
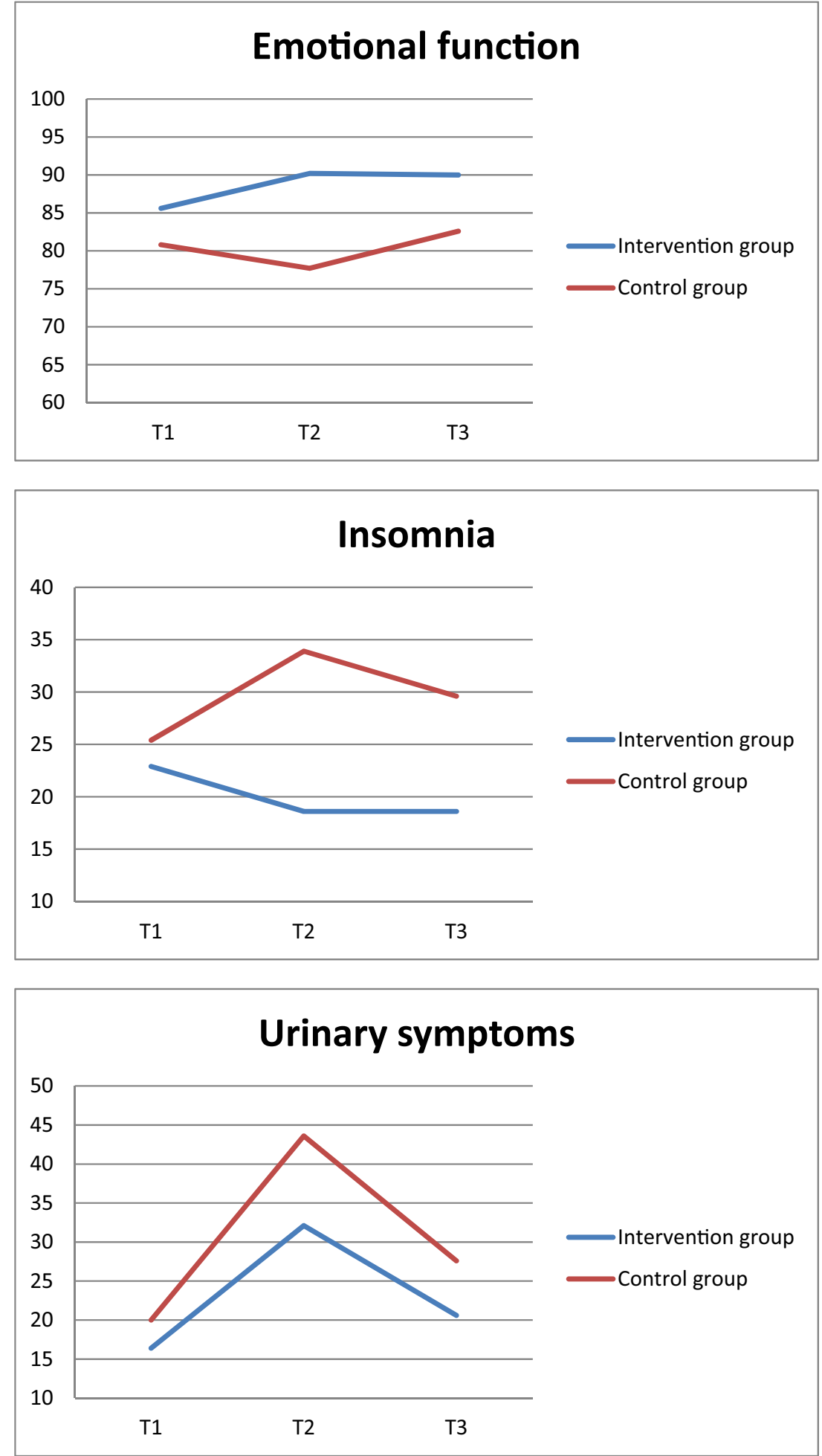

Few studies discuss clinical as well as cost effectiveness in relation to mHealth [39] which is imperative before implementing in clinical care. We show that using our app render less symptom burden, which confirms a concrete value for the patients. Patient satisfaction of using the app warrants further investigation although high acceptability and user- friendliness of the app were previously shown in our feasibility studies [17, 40]. However, evaluations in full RCT studies are required before general implementation.

In conclusion, reporting symptoms via the application seems to have had a positive effect on symptom burden and HRQoL in this group of patients with prostate cancer. An 
interactive application like Interaktor is unique, with its realtime communication enabling rapid management of symptoms when detected early. Our findings suggest that Interaktor could be an efficient mHealth tool for facilitating support needs during radiotherapy for prostate cancer.

\section{Compliance with ethical standards}

Conflict of interest The authors declare that they have no conflicts of interest. The first author has full control of all primary data and agrees to allow the journal to review the data if requested.

Open Access This article is distributed under the terms of the Creative Commons Attribution-NonCommercial 4.0 International License (http:// creativecommons.org/licenses/by-nc/4.0/), which permits any noncommercial use, distribution, and reproduction in any medium, provided you give appropriate credit to the original author(s) and the source, provide a link to the Creative Commons license, and indicate if changes were made.

\section{References}

1. LaSpina M, Haas GP (2008) Update on the diagnosis and management of prostate cancer. Can J Urol 15(Suppl 1):3-13 discussion 13

2. Fransson P, Lund JA, Damber JE, Klepp O, Wiklund F, Fossa S, Widmark A, Scandinavian Prostate Cancer Group S, Swedish Association for Urological O (2009) Quality of life in patients with locally advanced prostate cancer given endocrine treatment with or without radiotherapy: 4-year follow-up of SPCG-7/SFUO-3, an open-label, randomised, phase III trial. Lancet Oncol 10(4):370-380

3. Wei JT, Dunn RL, Sandler HM, McLaughlin PW, Montie JE, Litwin MS, Nyquist L, Sanda MG (2002) Comprehensive comparison of health-related quality of life after contemporary therapies for localized prostate cancer. J Clin Oncol 20(2):557-566

4. Boberg EW, Gustafson DH, Hawkins RP, Offord KP, Koch C, Wen KY, Kreutz K, Salner A (2003) Assessing the unmet information, support and care delivery needs of men with prostate cancer. Patient Educ Couns 49(3):233-242

5. Blomberg K, Wengström Y, Sundberg K, Browall M, Isaksson AK, Nyman MH, Langius-Eklöf A (2016) Symptoms and self-care strategies during and six months after radiotherapy for prostate cancer scoping the perspectives of patients, professionals and literature. Eur J Oncol Nurs 21:139-145

6. Hsiao CP, Moore IM, Insel KC, Merkle CJ (2014) Symptom selfmanagement strategies in patients with non-metastatic prostate cancer. J Clin Nurs 23(3-4):440-449

7. Sprangers MA (2010) Disregarding clinical trial-based patient-reported outcomes is unwarranted: five advances to substantiate the scientific stringency of quality-of-life measurement. Acta Oncol 49(2):155-163

8. U.S. Department of Health and Human Services (2009) U.S. Food and Drug Administration: Guidance for Industry: Patient-Reported Outcome measures: Use in medical product development to support labelling claims. http://www.fda.gov/downloads/Drugs/ GuidanceComplianceRegulatoryInformation/Guidances/ UCM193282.pdf. Retrieved on 21 Mar 2016

9. Kotronoulas G, Kearney N, Maguire R, Harrow A, Di Domenico D, Croy S, MacGillivray S (2014) What is the value of the routine use of patient-reported outcome measures toward improvement of patient outcomes, processes of care, and health service outcomes in cancer care? A systematic review of controlled trials. J Clin Oncol 32(14):1480-1501
10. Valderas JM, Kotzeva A, Espallargues M, Guyatt G, Ferrans CE, Halyard MY, Revicki DA, Symonds T, Parada A, Alonso J (2008) Theimpact of measuring patient-reported outcomes in clinical practice: a systematic review of the literature. Qual Life Res 17(2):179-193

11. Abaidoo B, Larweh BT, Consumer Health Informatics (2014) The application of ICT in improving patient-provider Partnership for a Better Health Care. Online J Public Health Inform 6(2):e188

12. Hilarius DLKP, Gundy CM, Aaronson NK (2008) Use of healthrelated quality-of-life assessments in daily clinical oncology nursing practice: a community hospital-based intervention study. Cancer 113(3):628-637

13. Ruland CM, Andersen T, Jeneson A, Moore S, Grimsbo GH, Borosund E, Ellison MC (2013) Effects of an internet support system to assist cancer patients in reducing symptom distress: a randomized controlled trial. Cancer Nurs 36(1):6-17

14. Seto E, Leonard KJ, Cafazzo JA, Barnsley J, Masino C, Ross HJ (2012) Mobile phone-based telemonitoring for heart failure management: a randomized controlled trial. J Med Internet Res 14(1): e31

15. McCann L, Maguire R, Miller M, Kearney N (2009) Patients' perceptions and experiences of using a mobile phone-based advanced symptom management system (ASyMS) to monitor and manage chemotherapy related toxicity. Eur J Cancer Care (Engl) 18(2):156-164

16. Wang J, Wang Y, Wei C, Yao NA, Yuan A, Shan Y, Yuan C (2014) Smartphone interventions for long-term health management of chronic diseases: an integrative review. Telemedicine journal and e-health : the official journal of the American Telemedicine Association 20(6):570-583

17. Sundberg K, Langius-Eklöf A, Blomberg K, Isaksson AK, Wengström Y (2015) Feasibility of an interactive ICT-platform for early assessment and management of patient-reported symptoms during radiotherapy for prostate cancer. Eur J Oncol Nurs 19(5):523-528

18. Regional Cancer Centrum:National Guideline for Prostate Cancer 2015-04-29, http://www.cancercentrum.se/samverkan/ cancerdiagnoser/prostata/vardprogram/gallande-vardprogram/ Retrieved 2016-12-23

19. Portenoy RK, Thaler HT, Kornblith AB, Lepore JM, FriedlanderKlar H, Kiyasu E, Sobel K, Coyle N, Kemeny N, Norton L et al (1994) The memorial symptom assessment scale: an instrument for the evaluation of symptom prevalence, characteristics and distress. Eur J Cancer 30A(9):1326-1336

20. Mårtensson L, Hensing G (2012) Health literacy - a heterogeneous phenomenon: a literature review. Scand J Caring Sci 26(1):151-160

21. Wångdahl JM, Mårtensson LI (2014) The communicative and critical health literacy scale-Swedish version. Scand J Public Health 42(1):25-31

22. Mårtensson 1 W J (2014) Skala för kommunikativ \& kritisk hälsolitteracitet. Handledning Göteborg 2014. Available from https://uploads.staticjw.com/ha/halsolitteracitet/manual-scchlskala-version-2-1-januari-2017.pdf

23. Aaronson NK, Ahmedzai S, Bergman B, Bullinger M, Cull A, Duez NJ, Filiberti A, Flechtner H, Fleishman SB, de Haes JC et al (1993) The European Organization for Research and Treatment of cancer QLQ-C30: a quality-of-life instrument for use in international clinical trials in oncology. J Natl Cancer Inst 85(5):365-376

24. van Andel G, Bottomley A, Fossa SD, Efficace F, Coens C, Guerif S, Kynaston H, Gontero P, Thalmann G, Akdas A et al (2008) An international field study of the EORTC QLQ-PR25: a questionnaire for assessing the health-related quality of life of patients with prostate cancer. Eur J Cancer 44(16):2418-2424

25. Antonovsky A (1987) Unraveling the mystery of health; how people manage stress and stay well. Jossey-Bass Publishers, San Francisco 
26. Eriksson M, Lindström B (2005) Validity of Antonovsky's sense of coherence scale: a systematic review. J Epidemiol Community Health 59(6):460-466

27. Eriksson M, Lindstrom B (2007) Antonovsky's sense of coherence scale and its relation with quality of life: a systematic review. J Epidemiol Community Health 61(11):938-944

28. Jakobsson L, Persson L, Lundqvist P (2013) Daily life and life quality 3 years following prostate cancer treatment. BMC Nurs 12:11

29. Fayers P, Aaronson NK, Bjordal K, Groenvold M (2001) The EORTC quality of life Stydy group, EORTC QLQ-C30 scoring manual vol, 3rd edn. European Organisation for Research and Treatment of Cancer, Brussels

30. Rohani C, Abedi HA, Omranipour R, Langius-Eklöf A (2015) Health-related quality of life and the predictive role of sense of coherence, spirituality and religious coping in a sample of Iranian women with breast cancer: a prospective study with comparative design. Health Qual Life Outcomes 13:40

31. Sanda MG, Dunn RL, Michalski J, Sandler HM, Northouse L, Hembroff L, Lin X, Greenfield TK, Litwin MS, Saigal CS et al (2008) Quality of life and satisfaction with outcome among prostate-cancer survivors. N Engl J Med 358(12):1250-1261

32. Trudel-Fitzgerald C, Savard J, Ivers H (2014) Longitudinal changes in clusters of cancer patients over an 18-month period. Health Psychol 33(9):1012-1022

33. Mazzarello Moore TH, King AJ, Evans M, Sharp D, Persad R, Huntley AL (2015) Supportive care for men with prostate cancer: why are the trials not working? A systematic review and recommendations for future trials. Cancer Med 4(8):1240-1251
34. Pachman DR, Barton DL, Swetz KM, Loprinzi CL (2012) Troublesome symptoms in cancer survivors: fatigue, insomnia, neuropathy, and pain. J Clin Oncol 30(30):3687-3696

35. Hammer MJ, Ercolano EA, Wright F, Dickson VV, Chyun D, Melkus GD (2015) Self-management for adult patients with cancer: an integrative review. Cancer Nurs 38(2):E10-E26

36. Olsson LE, Jakobsson Ung E, Swedberg K, Ekman I (2013) Efficacy of person-centred care as an intervention in controlled trials - a systematic review. J Clin Nurs 22(3-4):456-465

37. Mielck A, Vogelmann M, Leidl R (2014) Health-related quality of life and socioeconomic status: inequalities among adults with a chronic disease. Health Qual Life Outcomes 12:58

38. Cnossen IC, van Uden-Kraan CF, Eerenstein SE, Jansen F, Witte BI, Lacko M, Hardillo JA, Honings J, Halmos GB, GoedhartSchwandt NL et al (2016) An online self-care education program to support patients after total laryngectomy: feasibility and satisfaction. Support Care Cancer 24(3):1261-1268

39. Boulos MN, Brewer AC, Karimkhani C, Buller DB, Dellavalle RP (2014) Mobile medical and health apps: state of the art, concerns, regulatory control and certification. Online J Public Health Inform 5(3):229

40. Algilani S, Langius-Eklöf A, Kihlgren A, Blomberg K (2016) An interactive ICT-platform for early assessment and management of patient-reported concerns among older adults living in ordinary housing - development and feasibility. J Clin Nurs. doi:10.1111/ jocn. 13468 